\title{
Applying Modularity Theory \\ to Music Business Programs or How I Learned to Innovate Strategic Planning Processes to Align Mission, Vision, and Values to Shifting Market Needs and Expectations and Create Better Business Models in Higher Education
}

\author{
Joseph J. Miglio \\ Berklee College of Music \\ This paper was presented at the 2018 International Summit of the \\ Music \& Entertainment Industry Educators Association \\ March 22-24, 2018
}

$\underline{\text { https://doi.org/10.25101/18.16 }}$

\section{Abstract}

There is an ever-growing urgency to address the changing times in higher education through the prism of its business model. It is one that emphasizes its four key components: its value proposition, the utilization of its resources, determining models of efficiency, effectiveness, and efficacy for its processes, and measuring its ability to profit in a consistent and predictive formula. Beginning with the discussion offered in Disrupting College (Clayton M. Christensen 2011) and continued in its research collaborations by the Christensen Institute, all of these components must fit together in an interdependent way in order for the business model, in each of its components, to be viable. It is with that understanding that this presentation looks at Modularity Theory -independent (module) and interdependency as model for academic program review and development.

Modularity Theory is a framework for explaining how different parts of a product's architecture relate to one another and affect the metrics of its production and adoption/ use. A product is modular when there are no unpredictable elements in the design of its parts, it standardizes the way by which components fit together, in well-understood, measured ways. A product is interdependent when the way one part is made and delivered depends on the way other parts are made and delivered. Interdependency between parts requires the same organization to develop both components if it hopes to develop either component. So, what if we were to consider the following assumption: A course is product.
A major is product. A degree is product. How and in what ways are we recognizing the independent product architectures? Is there modularity? Interdependence? What/where are the breakthroughs and breakdowns in the institutional/ degree reputation and brand that could be re-innovated with applying modularity theory to our business modeling strategies?

In this session we will discuss a model of academic strategic planning model that is narrative and data driven that asks: What if we were to think about innovation differently, starting, rather than ending, with a modularity lens? It has the capacity to become a model of inquiry that equally addresses program relevancy, product differentiation and degree legitimacy by design (in all senses of that word!) at a time when the four key components are being challenged. A suggested template for initiation of this modularity model of strategic planning and business modeling will be provided.

Keywords: higher education, modularity theory, academic program review, academic planning, educational innovation

Joseph (Joe) Miglio is an Associate Professor of Music Business/Management at Berklee College of Music, with areas of expertise including leadership and design thinking, strategic planning and business development, product development, and performance measurements. Dr. Miglio has presented at multiple national conferences on topics such as artist identity and income generation, personal brand marketing strategies, start up to scale up businesses models, competitive analysis and value propositions, trend analysis/ 
forecasting and innovative design. In 2012, Joe received the Distinguished Faculty Award for the Professional Education Division at Berklee based on his outstanding commitment to teaching, dedication to his students, and contributions to the curriculum. He was instrumental in the design and facilitation of the Professional/Career Development Seminar-its purpose to investigate and address common challenges associated with artist development and sustainable business models that align with the core values of the artist and creating profitability for that individual. This course is now required for all Berklee students. Joe has interviewed a variety of artist/musicians/business leaders including Janis Ian, John Oates, Victor Wooten, John Clayton, Ernie Isley, and Grace Kelly, looking at how their individual stories can find a common narrative in personal and professional advancement. Joe has a Doctorate in Education from National Louis University in Chicago and is the creator of the Reflexive Engagement Method, a model of inquiry based on self-knowledge construction and transpersonal understanding. His most recent work is based on the dual concept: "life is a conversation and life as a conversation."

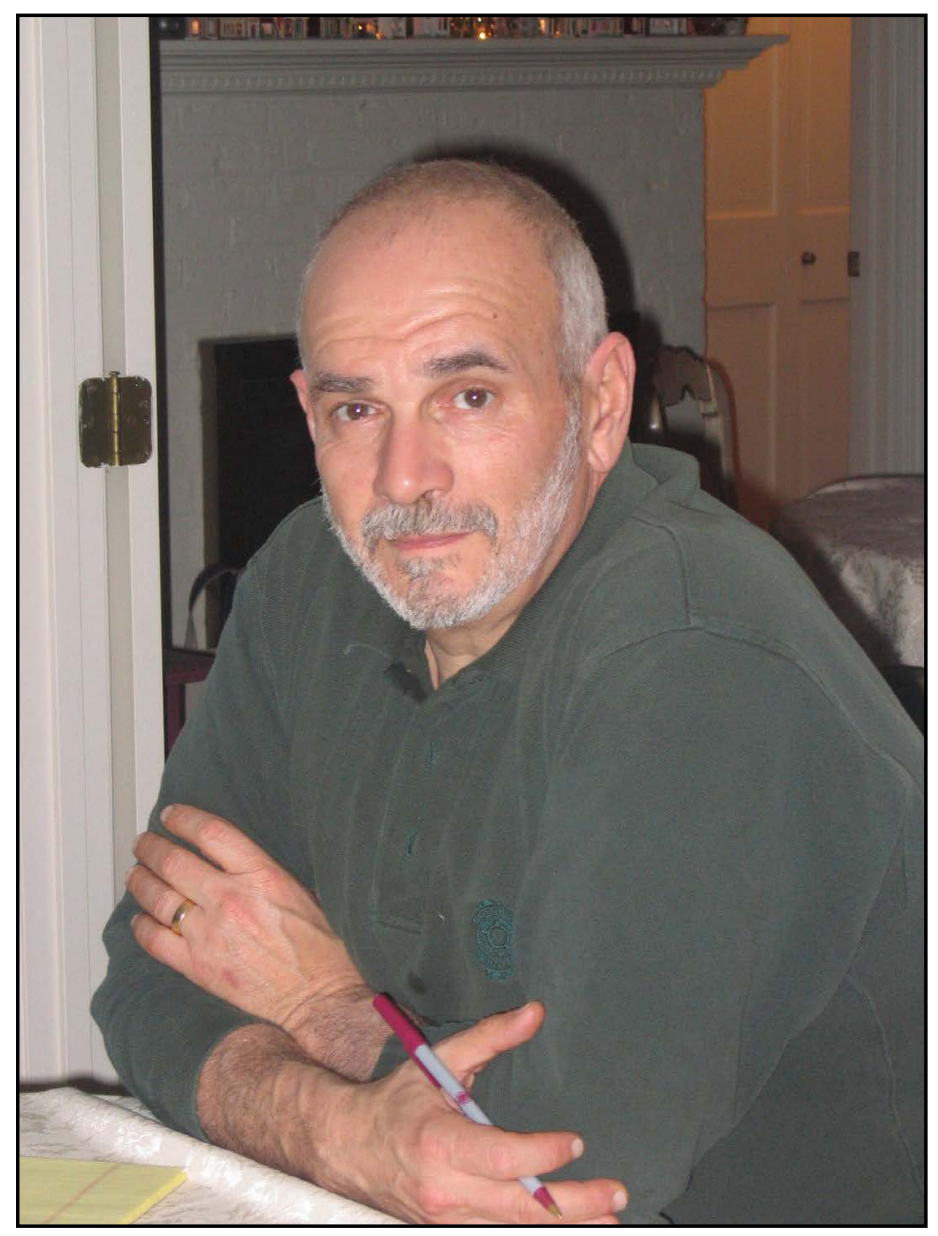




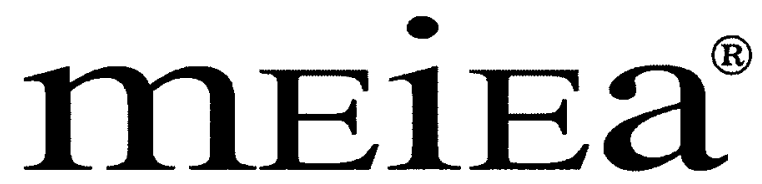

MUSIC \& ENTERTAINMENT INDUSTRY

EDUCATORS ASSOCIATION

\section{PROCEEDINGS OF THE \\ 2018 INTERNATIONAL SUMMIT}

OF THE

\section{MUSIC \& ENTERTAINMENT INDUSTRY EDUCATORS \\ ASSOCIATION}
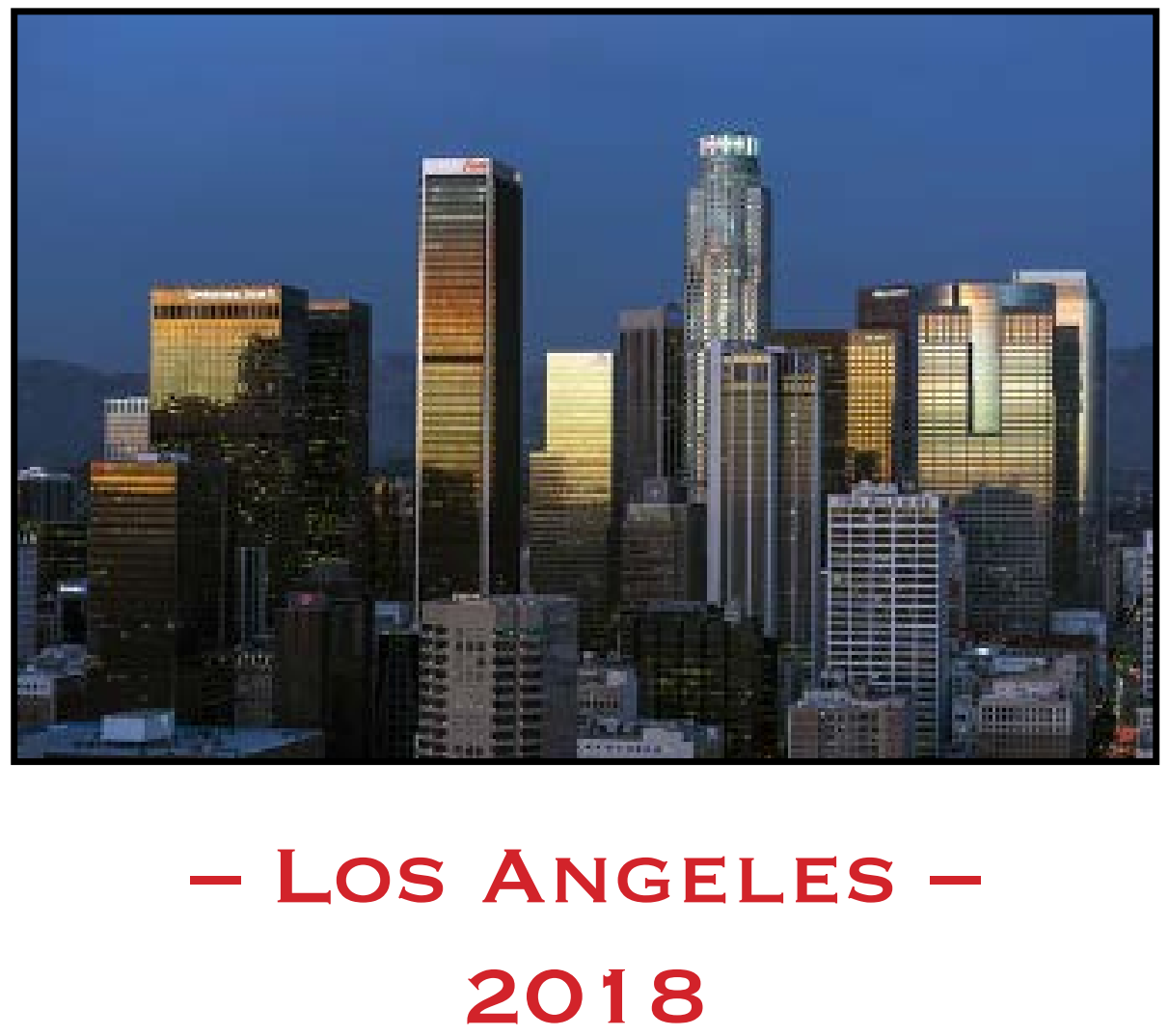

March 22 - 24, $2018 \cdot$ Embassy Suites by Hilton - Los Angeles/Glendale 